\title{
Effects of a Bovine Alpha S1-Casein Tryptic Hydrolysate (CTH) on Sleep Disorder in Japanese General Population
}

\author{
Zara de Saint-Hilaire*, ${ }^{*}$, Michaël Messaoudi ${ }^{2}$, Didier Desor ${ }^{3}$ and Toshinori Kobayashi ${ }^{4}$ \\ ${ }^{I}$ Department de Psychiatrie Adulte, Sleep Center, Hopitaux Universitaires de Genève, Belle-Idée, 1225, Chêne-Bourg, \\ Switzerland \\ ${ }^{2}$ ETAP-Ethologie Appliquée, Technopôle de Nancy-Brabois, 54500 Vandoeuvre-lès-Nancy, France \\ ${ }^{3}$ Laboratoire de Neurosciences Comportementales, URAFPA, INRA, 54500 Vandoeuvre-lès-Nancy, France \\ ${ }^{4}$ Ashikaga Institute of Technology, 268-1 Omaecho, Ashikaga City, Tochigi, 326-8558 Japan
}

\begin{abstract}
This study describes the effect of bovine alpha-S1 casein tryptic hydrolysate (CTH) in a representative sample of day-time workers from the general population of Japan with the occurrence of insomnia during the preceding six months. To investigate this issue, 32 subjects, aged between 25 and 40 years, were examined for the subjective sleep quality using the Japanese Pittsburg Sleep Quality Index (PSQI-J).

CTH significantly improves the PSQI total score of the treated subjects. It particularly improves the sleep quality after two weeks of treatment, decreases the sleep latency and the daytime dysfunction after four weeks of treatment.

Given the antistress properties of $\mathrm{CTH}$, it seems possible to relate the detected improvement of sleep aspects to a reduction of stress following its' chronic administration.

In conclusion, being given its beneficial effects and its absence of negative side effects, it would be advantageous to use the CTH to improve chronic insomnia in the Japanese general population. However, further studies will be necessary in order to clarify the essential aspect of CTH properties in the sleep problems.
\end{abstract}

Keywords: Alpha-S1 casein tryptic hydrolysate, Sleep, PSQI, Human, Japan.

\section{INTRODUCTION}

Difficulties in falling asleep, in staying asleep, waking up too early every morning, are the main symptoms of insomnia. In the last years, numerous studies indicated that about $25-36 \%$ of adults in the general population suffer of transient or occasional insomnia [1-6]. Chronic insomnia was reported in $7.5-15 \%$ of adult people. It is well known that insomnia can lead to many adverse consequences at individual and societal levels. At the individual level, chronic sleep debt leads to daytime fatigue and tiredness, impairments in cognitive functions like lacks of concentration and memory loss $[7,8]$. In the emotional area, stress, anxiety and depression are commonly reported by insomniac people [9-11]. Moreover, recent studies have concluded that sleep deficits can facilitate the development of chronic metabolic disorders such as obesity, diabetes, and hypertension [12, 13]. At the societal level, insomnia leads to impaired work performance, absenteeism, lost productivity, and increased work-related accidents [8], increased health care costs and reduced quality of life $[14,15]$.

Particularly in Japan, it has been reported that the prevalence of insomnia in the general population is comparable to

*Address correspondence to this author at the Department of Adult Psychiatry, Sleep Center, Hopitaux Universitaires de Genève, Belle-Idée, 1225, Chêne-Bourg, Switzerland; Tel: 0033671980154; Fax: 0041223055342; E-mail: desainthilairezara@gmail.com that reported in Western countries studies [16-18]. In addition, it was reported from a recent survey that one in five Japanese and one in three elderly Japanese suffer from insomnia [19]. The respective prevalence rates of sleep problems were estimated to $26.4 \%$ for males and $31.1 \%$ for females [20] and that approximately $23.6 \%$ of adult Japanese male and female daytime workers experienced insomnia lasting more than 6 months and that insomnia was associated with multiple psychosocial factors as psychological stress and job stress [21-23]. Insomnia affects Japanese society [24-26] and it is becoming a serious social problem [27, 28], leading the Ministry of Health, Labor and Welfare in Japan to propose a plan called "Health Japan 21", which adopted sleep as one of the specific living habits needing improvement. Insomnia is considered to be chronic if it occurs on three nights a week for one month or longer.

The most commonly occurring forms of chronic insomnia are associated with stress, anxiety and mild depression $[29,30]$. Stress and anxiety affect certain aspects of sleep with some consistency [31] and several alterations are described in the literature: changes of sleep/wake rhythm and modifications both in sleep duration and in sleep architecture [32].

Knowing that the most commonly occurring forms of chronic insomnia are associated with stress, anxiety and mild depression [9, 33, 10], we can postulate that treatments which reduce stress could be beneficial to people suffering from sleep disorders. 
In the 1960s, the benzodiazepines were introduced for the treatment of anxiety and insomnia. These medications were shown to have undesirable effects including amnesia, ataxia, tiredness, nausea, hypotension, leucopenia, hostility, confusion and depression [34], tolerance and dependence [35, 36]. Benzodiazepines are still in use today for the treatment of insomnia. They are less often prescribed now than in the past, however, because of those concerns regarding abuse and dependence, memory and movement impairment, next day "hangover" plus residual effects [37].

In the 1990s a newer class of medications, known as "non-benzodiazepine, benzodiazepine receptor agonists" were introduced for the treatment of insomnia [38, 39]. Although highly effective in promoting sleep and seeming to have better safety profiles, these drugs are however associated with residual side-effects.

An alternative approach is to focus on natural substances. Cow's milk has long been considered by folk wisdom as a tranquillizing beverage facilitating sleep. Since, it was reported that adults consuming a meal of cornflakes and milk exhibited a stronger tendency toward uninterrupted sleep [40] and it was shown that evening intake of lactalbumin may improve sleep and morning alertness [41].

Recently, it was discovered that a tryptic hydrolysate from bovine $\alpha \mathrm{S} 1$-casein, containing a decapeptide [ $\alpha \mathrm{S} 1$ casein (f91-100) termed $\alpha$-casozepine], displayed anxiolyticlike effects in rats $[42,43]$ and improves sleep in rats subjected to chronic mild stress [44]. In healthy human volunteers, this tryptic hydrolysate showed anxiolytic-like effects, without side effects, on the basis of hemodynamic parameters under mentally and physically stressful situations [45]. A recent study showed that a 30-day ingestion of $\alpha \mathrm{S} 1$-casein tryptic hydrolysate decreased stress-related symptoms in women, particularly in digestive, cardiovascular, intellectual, emotional and social problems [46]. Thus, considering the deleterious link between stress, anxiety and sleep, we hypothesized that this $\alpha \mathrm{S} 1$-casein hydrolysate might also prevent or reduce the effects of stressful environmental conditions on sleep. Good sleep quality has been associated with better physical health [47, 48] and greater psychological well-being $[49,50]$. Therefore, factors that affect sleep quality could also influence the general well-being of individuals. Consequently, the aim of the present study was to investigate whether the anxiolytic effect of CTH (i.e. the tryptic hydrolysate of bovine $\alpha \mathrm{S} 1$-casein) was accompanied by a proportional and concomitant improvement in sleep quality. For this purpose, a population of full-time job Japanese daytime working adults complaining for insomnia was given CTH over an extended period of 28 consecutive days. The evolution of sleep parameters were evaluated using the Japanese version of the Pittsburgh Sleep Quality Index (PSQI-J) $[51,52]$.

\section{METHODS}

\section{Subjects}

A total of 44 subjects from the pool of candidates of registered persons of Institute of General Health Development Co., Ltd. (Shiba Palace Clinic, Tokyo, Japan) participated in the present study.
The subjects were healthy Japanese men and women aged 25-40 and had reported sleeping disorders.

A medical doctor assessed medical history and sleeping disorders on the basis of an interview and a completed health and lifestyle questionnaire. The study was approved by a non-dependent ethics committee in accordance with the Helsinki Declaration of 1975 as revised in 1983 and corrected at the Edinburgh general meeting in 2000.

Following soul of the Welfare ministerial ordinance No.28 dated $27^{\text {th }}$ March 1997 "Ministerial ordinance about General standard on Clinical test implementation for Pharmaceuticals", this test shall aim at reservation of a subject's human right's and safety and reliability of the test data.

All subjects gave their oral and written informed consent to participate.

Were included, only subjects who were conscious of sleeping disorders, worked more than 4 days a week and sensed stressful in jobs, can enter in self-diagnoses paper and other documents, came to appointed institution on the visitto-the-hospital scheduled day, scored more than 5 in PSQI-J and relatively lower.

Were not included: those who are taking or who have taken within the past month hypnotic or sleep drugs, eat usually health food (teanin) considerably influencing the test result, under pregnancy or those who may be pregnant, and persons under breast-feeding, those who take more than 10 cups of green tea, coffee, tea and so on in a day totally (approx. $2 \mathrm{~L}$ ), those who are afraid to cause allergic symptoms (milk products), those who attend other clinical test, those who have a case history of critical liver obstacle, kidney obstacle and myocardial infarction, those who drink every day (quantity equivalent to one big bottle of beer $(633 \mathrm{ml})$, one unit of Japanese sake $(180 \mathrm{ml})$, one unit of white distilled liquor $(180 \mathrm{ml})$ or more, those who scored high in HAD scale (more than 8 points in HAD anxiety subscale) and those who get under 4 points in PSQI-J total score .

In total, 44 male and female subjects signed the informed consent. Of the eligible subjects, 32 subjects ( 25 women and 7 men) of which 20 consumed the test product and 12 consumed the placebo, were included on the basis of their anxiety HAD-subscale score (cut-off point 7/8) and their PSQI total score (> 4 points, indicating sleep disorder). The Japanese version of HAD scale is a sensitive and specific tool for screening for psychological distress in Japanese patients. The validity and reliability of the Japanese version of HAD scale have been confirmed previously $[53,54]$. The anxiety subscale of HAD also gave high sensitivity and specificity at the cut-off point $7 / 8$. This result supports the previous report [55].

\section{Tested Products}

The tested products were alpha-s1 casein hydrolysate (CTH) (lactium ${ }^{\mathrm{TM}}$, supplied by INGREDIA, Arras, France) and placebo (CBC Co., Ltd., Japan).

The content per capsule of the two products was shown in the Table 1.

Both products were administered in exactly the same capsule form containing either CTH or placebo. 
Table 1. Composition of CTH and Placebo Per Capsule

\begin{tabular}{|c|c|}
\hline CTH & Placebo \\
\hline \hline Protein: $112.50 \mathrm{mg}$ & Dextrin: $142.35 \mathrm{mg}$ \\
\hline Gelatin (protein): $53.11 \mathrm{mg}$ & Gelatin (protein): $53.11 \mathrm{mg}$ \\
\hline Minerals: $22.50 \mathrm{mg}$ & Moisture: $16.64 \mathrm{mg}$ \\
\hline Moisture: $17.39 \mathrm{mg}$ & Titanium dioxide: $0.76 \mathrm{mg}$ \\
\hline$\alpha_{\mathrm{s} 1}$-casein f91-100: $2.70 \mathrm{mg}$ & Ash: $0.15 \mathrm{mg}$ \\
\hline Fat: $1.50 \mathrm{mg}$ & \\
\hline Titanium dioxide: $0.76 \mathrm{mg}$ & \\
\hline Lactose: $0.75 \mathrm{mg}$ & \\
\hline
\end{tabular}

All the test products were consumed and therefore compliance for study substance intake was considered $100 \%$. The subjects completed the forms and consumed the test substances as planned. No serious adverse events were reported.

\section{Experimental Design}

The study was designed as a double-blind, controlled, parallel study of five weeks in total, including a follow-up period of one week. In the follow-up week we evaluated if parameters returned to baseline values. This study, conducted in the Shiba Palace Clinic, Tokyo, Japan, was intended to carry out evaluation of efficacy on sleepingdisorder improvement of CTH using the PSQI-J.

Between Day 1 and Day 28, the four-week study period, each subject daily ingested one capsule 1 hour before going to bed together with cold or warm water.

The subjects completed the PSQI-J, before treatment intake (D0), after two weeks (D14), after four weeks (D28) and one week after the follow-up week (D35).

The PSQI is a self-rated questionnaire which assesses sleep quality and disturbances over a 1-month time interval. Nineteen individual items generate seven component scores: sleep quality, sleep latency, sleep duration, habitual sleep efficiency, sleep disturbances, use of sleeping medication, and daytime dysfunction. The sum of scores for these seven components (range of score 0-3) allows to determine a global score of subjective sleep quality.

\section{Statistics}

Only the data from subjects who completed the entire PSQI-J at the four sessions were used for the present analy- sis. All raw data were delivered on paper and entered using a double data-entry.

The Statview statistical software package V5.0 (SAS institute Inc., USA) was used for statistical analysis. Comparisons between the parameters of the two groups were performed using the Mann-Whitney U-test. The repeated measures were investigated using the Friedman's test. If the Friedman indicated a treatment effect $(\mathrm{P}<0.05)$, comparisons between D0 and D14, D28 and D35 were performed using Wilcoxon rank test. Since the probability of a type I error is increased with multiple comparisons, we used the Bonferroni inequality formula to adjust our alpha level. We divided an initial type I error rate of 0.05 by 6 (the number of independent comparisons per group) and set our level of statistical significance at $\mathrm{P}=0.008$.

\section{RESULTS}

\section{PSQI Total Score}

As shown in Table 2, the Mann-Whitney U-test did not show significant differences between $\mathrm{CTH}$ and Placebo groups in PSQI-J total scores at D0 (U=85; NS), D14 (U=86.5; NS), D28 (U=98.5; NS) and D35 (U=99.5; NS). In CTH group, the Friedman's test showed a significant difference between the three test sessions $\left(\chi 2_{(3 \mathrm{df})}=30.25\right.$; $\mathrm{P}<0.0001)$ and significant improvements in PSQI-J total scores were observed using Wilcoxon rank test at D14 $(\mathrm{z}=2.63 ; \mathrm{P}=0.008), \mathrm{D} 28 \quad(\mathrm{z}=3.39 ; \mathrm{P}=0.0007)$ and $\mathrm{D} 35$ $(\mathrm{z}=3.22 ; \mathrm{P}=0.001)$ compared with $\mathrm{D} 0$. In Placebo group, the Friedman's test showed a significant difference between the three test sessions $\left(\chi 2_{(3 \mathrm{df})}=16.43 ; \mathrm{P}<0.0001\right)$, however no significant difference was observed at D14 $(\mathrm{z}=2.11$; NS) and at D28 and D35, the PSQI-J total scores only tended to be lower than that of D0.

\section{Sleep Quality}

As shown in Table 3, the Mann-Whitney U-test did not show significant differences between the sleep quality scores of CTH and Placebo groups at D0 (U=110.5; NS), D14 (U=108.5; NS), D28 (U=110; NS) and D35 (U=108.5; NS). In CTH group, the Friedman's test showed a significant difference between the three test sessions $\left(\chi 2_{(3 \mathrm{df})}=25.31\right.$; $\mathrm{P}<0.0001)$ and significant improvements in sleep quality scores were observed using Wilcoxon rank test at D14 $(\mathrm{z}=3.61 ; \mathrm{P}=0.0003), \mathrm{D} 28 \quad(\mathrm{z}=3.50 ; \mathrm{P}=0.0005)$ and $\mathrm{D} 35$ $(\mathrm{z}=3.15 ; \mathrm{P}=0.002)$ compared with $\mathrm{D} 0$. In Placebo group, the Friedman's test showed a significant difference between the three test sessions $\left(\chi 2_{(3 \mathrm{df})}=11.48 ; \mathrm{P}<0.009\right)$, however no significant difference was observed in sleep quality scores at

Table 2. Effects of CTH on PSQI Total Score (Median with IQR Values)

\begin{tabular}{|c|c|c|c|c|}
\hline $\begin{array}{c}\text { Test Session } \\
\text { Treatment }\end{array}$ & Do & D14 & D28 & D35 \\
\hline CTH $(n=20)$ & $\begin{array}{c}9 \\
(6.5-11.5)\end{array}$ & $\begin{array}{c}7 * \\
(5-9)\end{array}$ & $\begin{array}{c}5.5^{* * * *} \\
(3.5-7.5)\end{array}$ & $\begin{array}{c}5.5 * * \\
(4-7.5)\end{array}$ \\
\hline Placebo $(n=12)$ & $\begin{array}{c}7.5 \\
(6-8)\end{array}$ & $\begin{array}{c}5.5 \\
(4-7.5)\end{array}$ & $\begin{array}{c}5^{\mathrm{T}} \\
(2.5-7)\end{array}$ & $\begin{array}{c}5^{\mathrm{T}} \\
(3.5-6.75)\end{array}$ \\
\hline
\end{tabular}

Wilcoxon rank test: ${ }^{\mathrm{T}} \mathrm{P}<0.10 ; * \mathrm{P}<0.05 ; * * \mathrm{P}<0.01 ; * * * \mathrm{P}<0.005$ ( $\left.v s . \mathrm{D} 0\right)$. Alpha level was adjusted using the Bonferroni inequality formula. IQR: interquartile range. 
Table 3. Effects of CTH on Sleep Quality (Median with IQR Values)

\begin{tabular}{|c|c|c|c|c|}
\hline $\begin{array}{c}\text { Test Session } \\
\text { Treatment }\end{array}$ & Do & D14 & D28 & D35 \\
\hline \hline CTH (n=20) & 2 & $1^{* * * *}$ & $(1-1.5)$ & $(1-2)$ \\
\hline Placebo (n=12) & $(2-2)$ & $(1-2)$ & 1 & 1.5 \\
& 2 & 1.5 & $(1-2)$ & $(1-2)$ \\
\hline
\end{tabular}

Wilcoxon rank test: $* * \mathrm{P}<0.01 ; * * * \mathrm{P}<0.005$ (vs. D0); Alpha level was adjusted using the Bonferroni inequality formula. IQR: interquartile range.

$\mathrm{D} 14(\mathrm{z}=2.12 ; \mathrm{NS}), \mathrm{D} 28(\mathrm{z}=2.33 ; \mathrm{NS})$ and D35 $(\mathrm{z}=2.12 ; \mathrm{NS})$ in comparison with that of D0.

\section{Sleep Latency}

As shown in Table 4, the Mann-Whitney U-test did not show significant differences between the sleep latency scores of CTH and Placebo groups at D0 (U=103; NS), D14 (U=82.5; NS), D28 (U=88.5; NS) and D35 (U=86.5; NS). In CTH group, the Friedman's test showed a significant difference between the three test sessions $\left(\chi 2_{(3 \mathrm{df})}=18.91\right.$; $\mathrm{P}<0.0003)$ and significant improvements in sleep latency scores were observed using Wilcoxon rank test at D28 $(\mathrm{z}=3.09 ; \mathrm{P}=0.002)$ and $\mathrm{D} 35(\mathrm{z}=2.68 ; \mathrm{P}=0.008)$ compared with D0. No difference was observed at D14 ( $\mathrm{z}=1.30 ; \mathrm{NS})$. In Placebo group, the Friedman's test showed a significant difference between the three test sessions $\left(\chi 2_{(3 \mathrm{df})}=12.75\right.$; $\mathrm{P}<0.005)$, however no significant difference was observed in sleep latency scores at D14 ( $\mathrm{z}=1.93$; NS) and D35 ( $\mathrm{z}=2.16$; NS) in comparison with that of D0. The sleep latency score obtained at D28 tended to be lower than that of D0 $(\mathrm{z}=2.39$; $\mathrm{P}=0.017)$.

\section{Sleep Duration}

The Mann-Whitney U-test did not show significant differences between the sleep duration scores of CTH and Placebo groups at D0 (U=76.5; NS), D14 (U=79.5; NS), D28 (U=94.5; NS) and D35 (U=100.5; NS). In CTH group, the Friedman's test showed that the sleep duration scores of the three test sessions tended to be different $\left(\chi 2_{(3 \mathrm{df})}=7.44\right.$; $\mathrm{P}<0.06)$; however, even the sleep duration scores decreased at D28 $(\mathrm{z}=2.18 ; \mathrm{P}=0.03)$ and $\mathrm{D} 35(\mathrm{z}=2.14 ; \mathrm{P}=0.03)$ compared with that of D0, the differences were not significant. In Placebo group, the Friedman's test did not show significant differences between the sleep duration scores of the three test sessions $\left(\chi 2_{(3 \mathrm{df})}=0.60 ; \mathrm{P}=0.90\right)$.

\section{Habitual Sleep Efficiency}

The Mann-Whitney U-test did not show significant differences between the sleep duration scores of CTH and Placebo groups at D0 (U=93; NS), D14 (U=102; NS), D28 $(\mathrm{U}=108 ; \mathrm{NS})$ and D35 (U=99; NS). In CTH group, the Friedman's test showed significant differences in habitual sleep efficiency scores of the three test sessions $\left(\chi 2_{(3 \mathrm{df})}=11\right.$; $\mathrm{P}<0.01)$; however, even the sleep duration scores decreased at $\mathrm{D} 28(\mathrm{z}=2.27 ; \mathrm{P}=0.02)$ and $\mathrm{D} 35(\mathrm{z}=2.27 ; \mathrm{P}=0.02)$ compared with that of D0, the differences were not significant. In Placebo group, the Friedman's test did not show significant differences between the sleep efficiency scores of the three test sessions $\left(\chi 2_{(3 \mathrm{df})}=3 ; \mathrm{P}=0.39\right)$.

\section{Sleep Disturbances}

The Mann-Whitney U-test did not show significant differences between the sleep duration scores of CTH and Placebo groups at D0 (U=108; NS), D14 (U=115.5; NS), D28 (U=102; NS) and D35 (U=104; NS). In CTH group, the Friedman's test showed significant differences in sleep disturbances scores of the three test sessions $\left(\chi 2_{(3 \mathrm{df})}=17.40\right.$; $\mathrm{P}<0.0006)$ and a significant improvement in sleep disturbances score was observed using Wilcoxon rank test at D35 $(\mathrm{z}=3.16 ; \mathrm{P}=0.002)$. At 14 and $\mathrm{D} 28$, the Wilcoxon test showed that sleep disturbances scores tended to be improved compared with D0 $(\mathrm{z}=2.24 ; \mathrm{P}=0.03$ and $\mathrm{z}=2.45 ; \mathrm{P}=0.01$, respectively). In Placebo group, the Friedman's test did not show significant differences between the sleep disturbances scores of the three test sessions $\left(\chi 2_{(3 \mathrm{df})}=5 ; \mathrm{P}=0.17\right)$.

\section{Daytime Dysfunction}

The Mann-Whitney U-test did not show significant differences between the sleep duration scores of CTH and Placebo groups at D0 (U=111.5; NS), D14 (U=104.5; NS), D28 $(\mathrm{U}=105 ; \mathrm{NS})$ and $\mathrm{D} 35$ ( $\mathrm{U}=110$; NS). In CTH group, the Friedman's test showed significant differences in daytime

Table 4. Effects of CTH on Sleep Latency (Median with IQR Values)

\begin{tabular}{|c|c|c|c|c|}
\hline $\begin{array}{c}\text { Test Session } \\
\text { Treatment }\end{array}$ & Do & D14 & D28 & $1^{*}$ \\
\hline CTH (n=20) & 3 & 2 & $(1-2)$ & $2^{*}$ \\
& $(1-3)$ & $(1-3)$ & $1^{\mathrm{T}}$ & 1.5 \\
Placebo (n=12) & 2 & 1 & $(0-2)$ & $(1-1.5)$ \\
\hline
\end{tabular}

Wilcoxon rank test: ${ }^{\mathrm{T}} \mathrm{P}<0.10 ; * \mathrm{P}<0.05$ (vs. D0); Alpha level was adjusted using the Bonferroni inequality formula. IQR: interquartile range. 
dysfunction scores of the three test sessions $\left(\chi 2_{(3 \mathrm{df})}=11.26\right.$; $\mathrm{P}<0.01)$ and a significant improvement in daytime dysfunction score was observed using Wilcoxon rank test at D28 $(\mathrm{z}=2.89 ; \mathrm{P}=0.004)$. At 14 and $\mathrm{D} 35$, the daytime dysfunction scores decreased compared with $\mathrm{D} 0(\mathrm{z}=2.12 ; \mathrm{P}=0.03$ and $\mathrm{z}=1.89 ; \mathrm{P}=0.06$, respectively). However, the differences were not significant. In Placebo group, the Friedman's test showed significant differences between the daytime dysfunction scores of the three test sessions $\left(\chi 2_{(3 \mathrm{df})}=7.80 ; \mathrm{P}=0.05\right)$, however, at D14, D28 and D35, no significant improvement was observed in comparison with $\mathrm{D} 0 \quad(\mathrm{z}=0.82 ; \mathrm{P}=0.41$; $\mathrm{z}=1.67 ; \mathrm{P}=0.10$ and $\mathrm{z}=2.12 ; \mathrm{P}=0.03$, respectively).

\section{DISCUSSION}

Sleep is a physical and mental resting state in humans. It is a vital biological function, necessary for physical and emotional well-being. Sleep problems, particularly insomnia, rapidly induce impairments in many areas of physical, intellectual and affective aspects of life [8]. Concerning the causes of insomnia, the attention was drawn toward hyperarousal [32] which is central to modern models of primary insomnia [56]. It is assumed that hyperarousal in various areas (i.e. cognitive, emotional, neuroendocrine or cardiovascular,...) can be induced in vulnerable individuals by acute psychological/psychosocial stressors $[57,58]$. The insomnia would be connected with excessive and continual excitement of the central nervous system. A study reveals that a person suffering from insomnia is in permanent mode of reacting to stress [59].

Given that hyperarousal may be induced by stress, the purpose of this study was to investigate whether oral intake of $\alpha \mathrm{S} 1$-casein hydrolysate would improve various aspects of sleep in stressed Japanese insomniac male and female subjects.

In several cultures, drinking a glass of warm milk before going to bed is believed to facilitate sleep. Indeed, even if many of these reports are only anecdotal, several milk components, like tryptophan (precursor of serotonin, a neurotransmitter involved in sleep induction), can act upon sleep and magnesium [60,61]. More recently, a lot of bioactive peptides released during enzymatic digestion of milk proteins have revealed various interesting properties like calcium bio-transfer activity [62], opiate activity [63], immunomodulating activity [64, 65], anti-hypertensive activity [66] and anti-thrombotic activity [67]. CTH, a milk $\alpha \mathrm{S} 1-$ casein tryptic hydrolysate, has shown interesting properties (reduction of systolic blood pressure reaction and of cortisol increase) in healthy human volunteers facing mental and physical stress situations [45]. Moreover, this hydrolysate has shown an anxiolytic-like profile in rats, in two classical tests: the conditioned defensive burying $(\mathrm{CDB})$ test and the elevated plus maze [43]. These properties of CTH seem to be in connection with a decapeptide, the as1-casein-(f91-100) [42] that has been spatially modelled [68].

The results of the study provided evidence that the chronic administration of CTH during a 4-week period had significant effects on various aspects of sleep, as evaluated by the Japanese version of Pittsburgh Sleep Quality Index (PSQI-J) [52]. Opposite to placebo-treated subjects, who never reported significant improvements of their symptoms, the subjects treated with $\mathrm{CTH}$ showed a significant decrease of the PSQI-J total score after 14 days of treatment. This improvement was greater after 28 days of treatment, and was still perceptible one week after the cessation of the treatment. These effects reinforce the results obtained on some sleep parameters in rats [44].

Concerning the PSQI-J detailed components, the best improvement due to CTH was observed for the sleep quality score. Indeed, after two weeks of treatment, the seriousness of this symptom was significantly decreased, and this improvement remained for the three following weeks. The sleep latency was also significantly reduced after four weeks of CTH treatment, as for the daytime dysfunction. The sleep disturbances only indicated a statistical trend for improvement after a 28-day period of treatment and a significant improvement at D35.

The comparisons between the two groups with the test of Mann-Whitney did not show significant differences, probably because of the control product's placebo effect. Despite everything, the paired comparisons with the test of Wilcoxon show interesting effects of CTH on sleep disorders of the treated subjects.

At present, the exact mechanism of action of CTH on sleep disorders is not known. The tryptic hydrolysate has been shown to exhibit a benzodiazepine-like activity probably due to its affinity to the GABA-A receptor, without displaying side effects [42]. Given the anti-stress properties of $\mathrm{CTH}$, it seems possible to relate the detected improvement of sleep aspects to a reduction of stress following the chronic administration of the treatment. Further studies will be necessary in order to clarify this essential aspect of CTH properties on sleep. While waiting, to replace the therapeutic agents currently used as aids to sleep by the Japanese, in other words the pharmacological hypnotic-medication and alcohol [69], it would be more advantageous to use CTH because of its beneficial effects and its lack of negative side effects.

\section{REFERENCES}

[1] Dodge R, Cline MG, Quan SF. The natural history of insomnia and its relationship to respiratory symptoms. Arch Intern Med 1995; 155: 1797-800.

[2] Ancoli-Israel S, Roth T. Characteristics of insomnia in the United States: results of the 1991 National Sleep Foundation Survey. I. Sleep 1999; 22(Suppl 2): S347-S53.

[3] Bixler EO, Vgontzas AN, Lin HM, Vela-Bueno A, Kales A. Insomnia in central Pennsylvania. J Psychosom Res 2002; 53: 58992.

[4] Ohay on MM, Guilleminault C, Paiva T, et al. An international study on sleep disorders in the general population: methodological aspects of the use of the Sleep-EVAL system. Sleep 1997; 20: 1086-92.

[5] Ohayon MM, Caulet M, Priest RG, Guilleminault C. DSM-IV and ICSD-90 insomnia symptoms and sleep dissatisfaction. Br J Psychiatry $19971 ; 171: 382-8$.

[6] Ohayon MM, Caulet M, Guilleminault C. How a general population perceives its sleep and how this relates to the complaint of insomnia. Sleep 1997; 20: 715-23.

[7] Roth T, Ancoli-Israel S. Daytime consequences and correlates of insomnia in the United States: results of the 1991 National Sleep Foundation Survey. II. Sleep 1999; 22 (Suppl 2): S354-S8.

[8] Thase ME. Correlates and consequences of chronic insomnia. Gen Hospital Psychiatry 2005; 27: 100-12.

[9] Perlis ML, Giles DE, Mendelson WB, Bootzin RR, Wyatt JK. Psychophysiological insomnia: the behavioral model and a neurocognitive perspective. J Sleep Res 1997; 6: 179-88. 
[10] Sukegawa T, Itoga M, Seno H, et al. Sleep disturbances and depression in the elderly in Japan. Psychiatry Clin Neurosci 2003; 57: 265-70.

[11] Kaneita Y, Uchiyama M, Takemura S, et al. Use of alcohol and hypnotic medication as aids to sleep among the Japanese general population. Sleep Med 2007; 8: 723-32.

[12] Spiegel K, Leproult R, Van Cauter E. Impact of sleep debt on metabolic and endocrine function. Lancet 1999; 4: 435-9.

[13] Hayashino Y, Fukuhara S, Suzukamo Y, Okamura T, Tanaka T, Ueshima H. Relation between sleep quality and quantity, quality of life, and risk of developing diabetes in healthy workers in Japan: the High-risk and Population Strategy for Occupational Health Promotion (HIPOP-OHP) Study. BMC Public Health 2007; 7: 129.

[14] Stoller MK. Economic effects of insomnia. Clin Ther 1994; 16: 873-97.

[15] Simon G, VonKorff M. Prevalence, burden, and treatment of insomnia in primary care. Am J Psychiatry 1997; 154: 1417-23.

[16] Liu XC, Uchiyama M, Kim K, et al. Sleep loss and daytime sleepiness in the general adult population of Japan. Psychiatry Res 2000; 93: 1-11.

[17] Nakata A, Haratani T, Takahashi M, et al. Job stress, social support, and prevalence of insomnia in a population of Japanese daytime workers. Soc Sci Med 2004; 59: 1719-30.

[18] Murata C, Yatsuya H, Tamakoshi K, Otsuka R, Wada K, Toyoshima $\mathrm{H}$. Psychological factors and insomnia among male civil servants in Japan. Sleep Med 2007; 8: 209-14.

[19] Tanaka H, Shirakawa S. Sleep health, lifestyle and mental health in the Japanese elderly; Ensuring sleep to promote a healthy brain and mind. J Psychosom Res 2004; 56: 465-77.

[20] Doi Y, Minowa M, Uchiyama M, Okawa M. Subjective sleep quality and sleep problems in the general Japanese adult population. Psychiatry Clin Neurosci 2001; 55: 213-5.

[21] Suka M, Yoshida K, Sugimori H. Persistent Insomnia is a Predictor of Hypertension in Japanese Male Workers. J Occup Health 2003; 45: 344-50.

[22] Ota A, Masue T, Yasuda N, Tsutsumi A, Mino Y, Ohara H. Association between psychosocial job characteristics and insomnia: an investigation using two relevant job stress models-the demandcontrol-support (DCS) model and the effort-reward imbalance (ERI) model. Sleep Med 2005; 6: 353-8.

[23] Utsugi M, Saijo Y, Yoshioka E, et al. Relationships of occupational stress to insomnia and short sleep in Japanese workers. Sleep 2005; 28: 728-35.

[24] Kaneita Y, Ohida T, Uchiyama M, et al. Excessive daytime sleepiness among the Japanese general population. J Epidemiol 2005; 15 : $1-8$.

[25] Kawada T, Yosiaki S, Yasuo K, Suzuki S. Population study on the prevalence of insomnia and insomnia-related factors among Japanese women. Sleep Med 2003; 4: 563-7.

[26] Kim K, Uchiyama M, Okawa M, Liu XC, Ogihara R. An epidemiological study of insomnia among the Japanese general population. Sleep 2000; 23: 41-7.

[27] Kageyama T, Kabuto M, Nitta H, et al. A population study on risk factors for insomnia among adult Japanese women: A possible effect of road traffic volume. Sleep 1997; 20: 963-71.

[28] Ishigooka J, Suzuki M, Isawa S, Muraoka H, Murasaki M, Okawa M. Epidemiological study on sleep habits and insomnia of new outpatients visiting general hospitals in Japan. Psychiatry Clin Neurosci 1999; 53: 515-22.

[29] Benca RM. Mood disorders. In: Kryger T, Dement WC, editors. Principles and practice of sleep medicine. Philadelphia: WB Saunders; 2000; pp. 1140-57.

[30] De Saint Hilaire Z, Straub J, Pelissolo A. Temperament and character in primary insomnia. Eur Psychiatry 2005; 20: 188-92.

[31] Vollrath M, Wicki W, Angst J. The Zurich study. VIII. Insomnia: association with depression, anxiety, somatic syndromes, and course of insomnia. Eur Arch Psychiatry Neurol Sci 1989; 239: 113-24.

[32] Bonnet MH, Arand DL. Hyperarousal and insomnia. Sleep Med Rev 1997; 1: 97-108.

[33] Hall M, Buysse DJ, Nowell PD, et al. Symptoms of stress and depression as correlates of sleep in primary insomnia. Psychosom Med 2000; 62: 227-30.

[34] Olajide D, Lader M. Depression following withdrawal from longterm benzodiazepine use: a report of four cases. Psychol Med 1984; 14: $937-40$.
[35] Power KG, Jerrom DW, Simpson RJ, Mitchell M. Controlled study of withdrawal symptoms and rebound anxiety after six week course of diazepam for generalised anxiety. Br Med J (Clin Res Ed) 1985; 290: $1246-8$.

[36] Rosenberg HC, Chiu TH. Time course for development of benzodiazepine tolerance and physical dependence. Neurosci Biobehav Rev 1985; 9: 123-31.

[37] Staner L, Ertlé S, Boeijinga P, et al. Next-day residual effects of hypnotics in DSM-IV primary insomnia: a driving simulator study with simultaneous electroencephalogram monitoring. Psychopharmacology (Berl) 2005; 181: 790-8.

[38] Doi Y, Minowa M, Uchiyama M, Okawa M. Sleep-medication for symptomatic insomnia in the general population of Japan. Sleep Biological Rhythms 2005; 3: 149-57.

[39] Bain KT. Management of chronic insomnia in elderly persons. Am Am J Geriatr Pharmacother 2006; 4: 168-92.

[40] Laird DA, Drexel H. Experimenting with food and sleep. I. Effects of varying types of foods in offsetting sleep disturbances caused by hunger pangs and gastric distress-children and adults. J Am Diet Assoc 1934; 10: 89-94.

[41] Markus CR, Jonkman LM, Lammers JH, Deutz NE, Messer MH, Rigtering NE. Evening Intake of Lactalbumin May Improve Sleep and Morning Alertness. Am J Clin Nutr 2005; 81: 1026-33.

[42] Miclo L, Perrin E, Driou A, et al. Characterization of $\alpha$-casozepine, a tryptic peptide from bovine $\alpha$ s1-casein with benzodiazepine-like activity. FASEB J 2001; 15: 1780-2.

[43] Violle N, Messaoudi M, Lefranc-Millot C, et al. Ethological comparison of the effects of a bovine $\alpha$ s 1-casein tryptic hydrolysate and diazepam on the behaviour of rats in two models of anxiety. Pharmacol Biochem Behav 2006; 84: 517-23.

[44] Guesdon B, Messaoudi M, Lefranc-Millot C, Fromentin G, Tome D, Even PC. A tryptic hydrolysate from bovine milk alpha(S1)casein improves sleep in rats subjected to chronic mild stress. Peptides 2006; 27: 1476-82.

[45] Messaoudi M, Lefranc-Millot C, Desor D, Demagny B, Bourdon L. Effects of a tryptic hydrolysate from bovine milk $\alpha_{S_{1} \text {-casein on }}$ hemodynamic responses in healthy human volunteers facing successive mental and physical stress situations. Eur J Nutr 2005; 44: 128-32.

[46] Kim JH, Desor D, Kim YT, et al. Efficacy of alphas1-casein hydrolysate on stress-related symptoms in women. Eur J Clin Nutr 2007; 61: 536-41.

[47] Barton J, Spelten E, Totterdell P, Smith L, Folkard S. Is there an optimum number of night shifts? Relationship between sleep, health and well-being. Work Stress 1995; 9: 109-23.

[48] Lewin DS, Dahl RE. Importance of sleep in the management of pediatric pain. Dev Beh Pediatr 1999; 20: 244-52.

[49] Bliwise NG. Factors related to sleep quality in healthy elderly women. Psychol Aging 1992; 7: 83-8.

[50] Shaver JL, Paulsen VM. Sleep, psychological distress, and somatic symptoms in perimenopausal women. Fam Pract Res J 1993; 13: 373-384.

[51] Buysse DJ, Reynolds CF, Monk TH, Berman SR, Kupfer DJ. The Pittsburgh Sleep Quality Index: A new instrument for psychiatric practice and research. Psychiatry Res 1989; 28: 193-213.

[52] Doi Y, Minowa M, Uchiyama M. Development of the Japanese version of the Pittsburgh Sleep Quality Index. Jpn J Psychiatry Treat (Seishinka Chiryogaku) 1998; 13: 755-63.

[53] Kugaya A, Akechi T, Okuyama T, Okamura H, Uchitomi Y. Screening for psychological distress in Japanese cancer patients. Jpn J Clin Oncol 1998; 28: 333-8.

[54] Hyodo I, Eguchi K, Takigawa N, et al. Psychological impact of informed consent in hospitalized cancer patients: A sequential study of anxiety and depression using the hospital anxiety and depression scale. Support Care Cancer 1999; 7: 396-9.

[55] Moorey S, Greer S, Watson M, Gorman C, Rowden L, Tunmore R. The factor structure and factor stability of the Hospital Anxiety and Depression Scale in patients with cancer. Br J Psychiatry 1991; 158: 255-9.

[56] Perlis ML, Giles DE, Buysse DJ, Tu X, Kupfer DJ. Self-reported sleep disturbance as a prodromal symptom in recurrent depression. J Affect Disord 1997; 42: 209-21.

[57] Leproult R, Copinschi G, Buxton O, Van Cauter E. Sleep loss results in an elevation of cortisol levels the next evening. Sleep 1997; 20: 865-70. 
[58] Tachibana H, Izumi T, Honda S, Takemoto TI. The prevalence and pattern of insomnia in Japanese industrial workers: Relationship between psychosocial stress and type of insomnia. Psychiatry Clin Neurosci 1998; 52: 397-402.

[59] Jansson M, Linton SJ. Psychological mechanisms in the maintenance of insomnia: Arousal, distress, and sleep-related beliefs. Behav Res Ther 2007; 45: 511-21.

[60] Minet-Ringuet J, LeRuyet PM, Tome D, Even PC. A tryptophanrich protein diet efficiently restores sleep after food deprivation in the rat. Behav Brain Res 2004; 152: 335-40.

[61] Hudson C, Hudson SP, Hecht T, MacKenzie J. Protein source tryptophan versus pharmaceutical grade tryptophan as an efficacious treatment for chronic insomnia. Nutr Neurosci 2005; 8: 1217.

[62] Lee YS, Noguchi T, Naito H. An enhanced intestinal absorption of calcium in the rat directly attributed to dietary casein. Agric Biol Chem 1979; 43: 2009-11.

[63] Meisel H, FitzGerakd RJ. Opioid peptides encrypted in intact milk protein sequences. Br J Nutr 2000; 84: S27-S31.
[64] Pitt J, Barlow D, Heird WC. Protection against experimental necrotizing enterocolitis by maternal milk. I. Role of milk leukocytes. Pediatr Res 1977; 11: 906-9.

[65] Tomita M, Takase M, Bellamy W, Shimamura S. A review: the active peptides of lactoferrin. Acta Paediatr Jpn 1994; 36: 585-91.

[66] Maruyama S, Mitachi H, Awaya J, Kurono M, Tomizuka N, Susuki $\mathrm{H}$. Angiotensin-converting enzyme inhibitory activity of the Cterminal hexapeptide of as1-casein. Agric Biol Chem 1987; 51: 2557-61.

[67] Chabance B, Jollès P, Izquierdo C, et al. Characterization of an anti-thrombotic peptide from $\alpha \mathrm{S} 1$-casein in newborn plasma after milk ingestion. Br J Nutr 1995; 73: 582-90.

[68] Lecouvey M, Frochot C, Miclo L, et al. Two dimensional H-MNR and CD structural analysis in a micellar medium of a bovine $\alpha$ s1casein fragment having benzodiazepine-like properties. Eur J Biochem 1997; 248: 872-8.

[69] Kaneita Y, Ohida T, Uchiyama M, et al. The relationship between depression and sleep disturbances: a Japanese nationwide general population survey. J Clin Psychiatry 2006; 67: 196-203.

(C) de Saint-Hilaire et al.; Licensee Bentham Open .

This is an open access article licensed under the terms of the Creative Commons Attribution Non-Commercial License (http://creativecommons.org/licenses/by-nc/3.0/) which permits unrestricted, non-commercial use, distribution and reproduction in any medium, provided the work is properly cited. 